\title{
Study of performance and emission characteristics of a compression ignition engine using tamarind biodiesel
}

\author{
D.Bahar $^{1 *}$, G.Kirti ${ }^{2}$, R.Mounika ${ }^{2}$ and S.Rajesham ${ }^{3}$ \\ Assistant Professor, Department of Mechanical Engineering, RGUKT-Basar, Nirmal (TS)-504107, India ${ }^{1}$ \\ Students, Department of Mechanical Engineering, RGUKT-Basar, Nirmal (TS)-504107, India ${ }^{2}$ \\ Professor, Department of Mechanical Engineering, RGUKT-Basar, Nirmal (TS)-504107, India ${ }^{3}$
}

\section{(C)2018 ACCENTS}

\begin{abstract}
The objective of this communication is to demonstrate engine performance, and emission characteristics of biodiesel used in compression ignition (CI) engines. Now a days biodiesels have been studied extensively and gaining huge importance as a promising alternative energy resource owing to global fossil fuel crisis and emission problems. India is the largest producer of tamarind (300000 tons annually) in world. Tamarind biodiesel is tested in four stroke single, single cylinder water cooled diesel engine and results are compared with pure diesel. From the results, it is reported that biodiesel (blends of Tamarind) containing up to $15 \%$ biodiesel have almost same properties as diesel and results have shown that as compare to diesel, biodiesel provides a slightly higher brake thermal efficiency(BTE) and volumetric efficiency, reduction in exhaust gas temperature (EGT) but the NOx emission are observed slightly higher. Biodiesels are anticipated to reduce the dependence on imported petroleum and revamp the economy by increasing demand and prices for agricultural products. From the review, it is also concluded that blends of biodiesel with a small content by volume can be used in existing CI engines without any modifications.
\end{abstract}

\section{Keywords}

Tamarind biodiesel, Brake thermal efficiency, Volumetric efficiency, Exhaust gas temperature, Oxides of nitrogen, Smoke density.

\section{Introduction}

At present, India is the biggest producer of tamarind in the world. Tamarind seed is a by-product obtained from the processing of tamarind fruit and may contain the oil yield of 20 to $40 \%$. In general, Tamarind seed oil is extracted by means of hexane over the tamarind seed and also by using solvent extraction technique. Every year availability of tamarind seed is in the range of 2,00,000-2,50,000 tons in India. The crude tamarind seed oil is highly viscous and low volatile. Figure 1 shows a sample of tamarind oil. The chemical reaction of fatty acids with alcohol results in to tamarind methyl ester and the glycerin. In the past few decades, fossil fuels, mainly petroleum-based liquid fuels, natural gas and coal have played an important role in fulfilling this energy demand. However, because of their nonrenewable nature, these fossil fuels are expected to be exhausted in future and further situation has worsened with the rapid increase in energy demand worldwide.

\footnotetext{
*Author for correspondence
}

Therefore, the demand for neat \& clean, sustainable and economically feasible renewable energy sources has led researchers to intensify research in this domain.

\subsection{Objectives}

1. To find a viable source of energy and consequently reduce the dependency on fossil fuel.

2. To find a clean fuel so that environmental pollution can be reduced

Dhana and Kishore [1] tested methyl ester of tamarind seed oil (TSME) blended with diesel. The best results are obtained for TSME 20 which showed lesser emissions comparable to other blends.

Dhana et al. [2] investigated performance, combustion and emission characteristics with three different methyl esters of biofuels and among them for Tamarind methyl ester the optimum conditions are obtained.

Patangi et al. [3] suggested that the biodiesel used is Tamarind and its blends with diesel fuel. The 
performance characteristics such as BSFC, BTE, volumetric ratio were found for blends B20, B40, B50, B60.The $60 \%$ blends performed well in running a diesel engine at a constant speed of $1500 \mathrm{rpm}$.

Pohit and Misra [4] performed with Karanja oil methyl ester. The performance and exhaust emissions were investigated and an attempt was made to optimize the engine responses using Taguchi method.

Nigade [5] used the blend of MadhucaIndica biodiesel. Grey relational theory is adopted to determine the best input parameters that give lower emissions.

Rao and Rao [6] tested blended Mahua methyl ester with ethanol and observed that $\mathrm{CO}$ and $\mathrm{HC}$ emission reduces while efficiency increases slightly.

Natarajan et al. [7] using grey relational grade and signal-to-noise ratio as a performance index, a combination of input parameters was prefigured so as to achieve optimum response characteristics.

Avinash et al. [8] worked on the optimization of performance and emission characteristics in diesel engine using biodiesel blend with Pongamia and found optimum operating parameters.

Venkatanarayana and Ratnam [9] suggested that the present study deals with the use of Taguchi approach to optimize. Biodiesel used is Karanja oil methyl ester called KOME.

Aydin and Bayindir [10] cottonseed oil methyl esterdiesel fuel with blends (B5, B20 and B50) are choosen. Results showed that with the increase of CSOME in the blends, the best results are obtained.

Gopinath et al. [11] conducted a study withrespect to injection pressure and number of holes at three levels with the diesel, waste cooking oil and rape seedoil. The optimum conditions are $30.31 \%$ for BTE and IP 190 bar.

Kumar et al. [12] suggested the response parameter BTE is optimized using Taguchi's methodology. The B80 blend is found to be most suitable blend for use in the diesel engine.

Kandasamy et al. [13] suggested that the biodiesel used is rice bran and pungam oil blended with diesel fuel i.e., B20, B40, B60. The performance of the engine is found to be good for the B40 blend.
Jawre and Lawankar [14] suggested that the Biodiesel used Iskusum methyl ester on the performance and emission of diesel engine at different load and constant speed. Thus optimum value is obtained.

Vasukumar et al. [15] suggested that the vegetable oil like bio-diesel, rice-bran oil, Sunflower oil, cotton seed oil can be used as a blended fuel. Ethanol can be used to improve performance and to reduce emission.

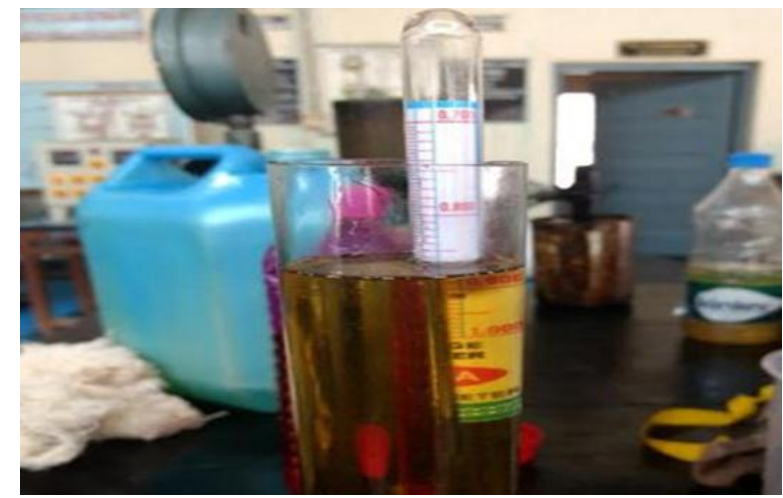

Figure 1 Tamarind bio-diesel (T100)

\section{Experimental procedure}

The experiment is performed using Tamarind biodiesel and also with neat diesel. Thus the comparison is made with the three different blends such as T5 (5\% Tamarind oil $+95 \%$ diesel), T10 $(10 \%$ Tamarind oil $+90 \%$ diesel) and T15 (15\% Tamarind oil $+85 \%$ diesel) at three different pressures 190bar,230bar and 270bar operated under three load conditions such as $0 \%, 60 \%$ and $100 \%$. Figure 2 shows a photographic view of the experimental setup and Table 1 presents the specification of this engine.

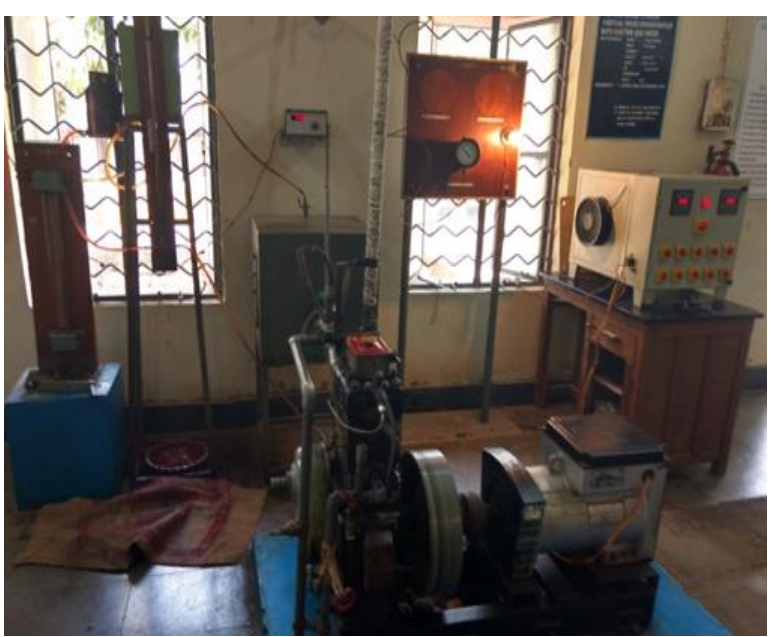

Figure 2 Photographic view of experimental setup 
Bahar et al.

Table 1 Specifications of engine used in the experiment

\begin{tabular}{ll}
\hline $\begin{array}{l}\text { Engine: kirloskar made, four-stroke, vertical, single- } \\
\text { cylinder, constant speed, water-cooled diesel engine. }\end{array}$ \\
\hline Bore & $80 \mathrm{~mm}$ \\
Stroke & $110 \mathrm{~mm}$ \\
Rated output & $3.68 \mathrm{~kW}$ \\
Rated speed & $1500 \mathrm{rpm}$ \\
Fuel injection timing & $27^{\circ} \mathrm{BTDC}$ \\
Fuel injection pressure & $190 \mathrm{bar}$ \\
Compression ratio & $16: 1$ \\
Combustion system & Open chamber \\
\hline
\end{tabular}

The Tamarind biodiesel properties density, Flash point, Fire point, Viscosity and Calorific value are measured and compared with pure diesel and ASTM standards. The properties of biodiesel are listed in Table 2 and density of various blends in Table 3 .

Table 2 Properties of biodiesel

\begin{tabular}{llll}
\hline $\begin{array}{l}\text { Fuel } \\
\text { properties }\end{array}$ & Units & Diesel & Bio-Diesel \\
\hline $\begin{array}{l}\text { Kinematic } \\
\text { viscosity }\end{array}$ & $\mathrm{mm}^{2} / \mathrm{sec}$ & 2.75 & 5 \\
$\begin{array}{l}\text { Density } \\
\text { Flash point }\end{array}$ & $\begin{array}{l}\mathrm{g} / \mathrm{cc} \\
{ }^{\circ} \mathrm{C}\end{array}$ & 0.83 & 0.86 \\
$\begin{array}{l}\text { Fire point } \\
\text { Calorific } \\
\text { value }\end{array}$ & $\mathrm{KJ} / \mathrm{Kg}$ & - & $>100-170$ \\
\hline
\end{tabular}

Table 3 Density of tamarind blends

\begin{tabular}{ll}
\hline Blends & Density(G/CC) \\
\hline T5 & 0.81 \\
T10 & 0.82 \\
T15 & 0.83 \\
\hline
\end{tabular}

In order to estimate the performance and emission characteristics following steps are followed:

Step 1: experiments were conducted with pure diesel.

Step 2: In the second phase of work, the engine was operated with diesel-Tamarind biodiesel blend ratio T5, T10, T15, injection operating pressures 190bar, 230bar and 270bar at different loading conditions.

Levels of varying parameters (Blend, Pressure and Load) are given in Table 4.

Table 4 Levels of varying parameters/factors

\begin{tabular}{llll}
\hline & \multicolumn{3}{l}{ Parameters/Factors } \\
\cline { 2 - 4 } Levels & Blend & Pressure(bar) & Load (\%) \\
\hline 1 & T5 & 190 & 0 \\
2 & T10 & 230 & 60 \\
3 & T15 & 270 & 100 \\
\hline
\end{tabular}

\section{Results and discussions}

Figure 3 demonstrates brake thermal efficiency (BTE) versus percentage of Tamarind blends at different Injection pressures. From figure it is clear that BTE increases with respect to percentage of Tamarind blend and BTE also increasing with injection pressure. Form Figure 4, it is observed that volumetric efficiency is higher in case of pure diesel and decreases after blend but exhibiting a nearly constant trend at different injection pressures.

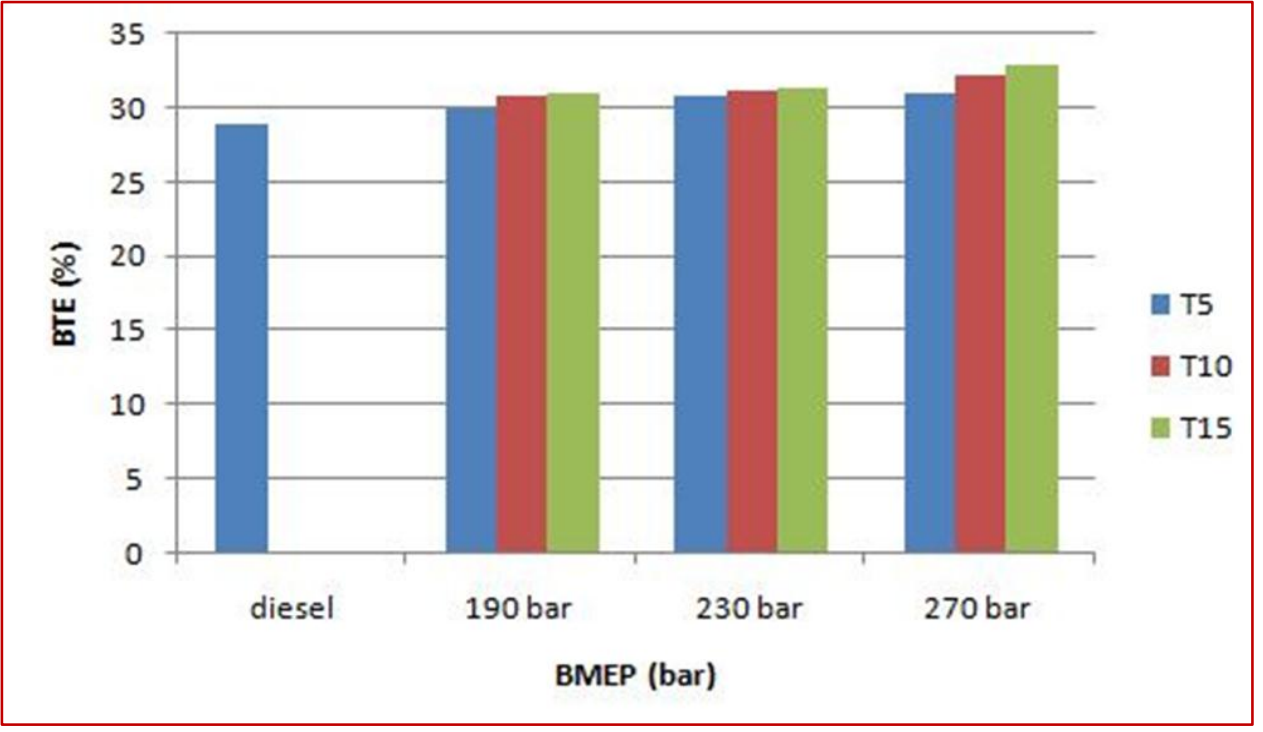

Figure 3 Demonstrates that corresponding to BTE, volumetric efficiency manifesting the similar trend 


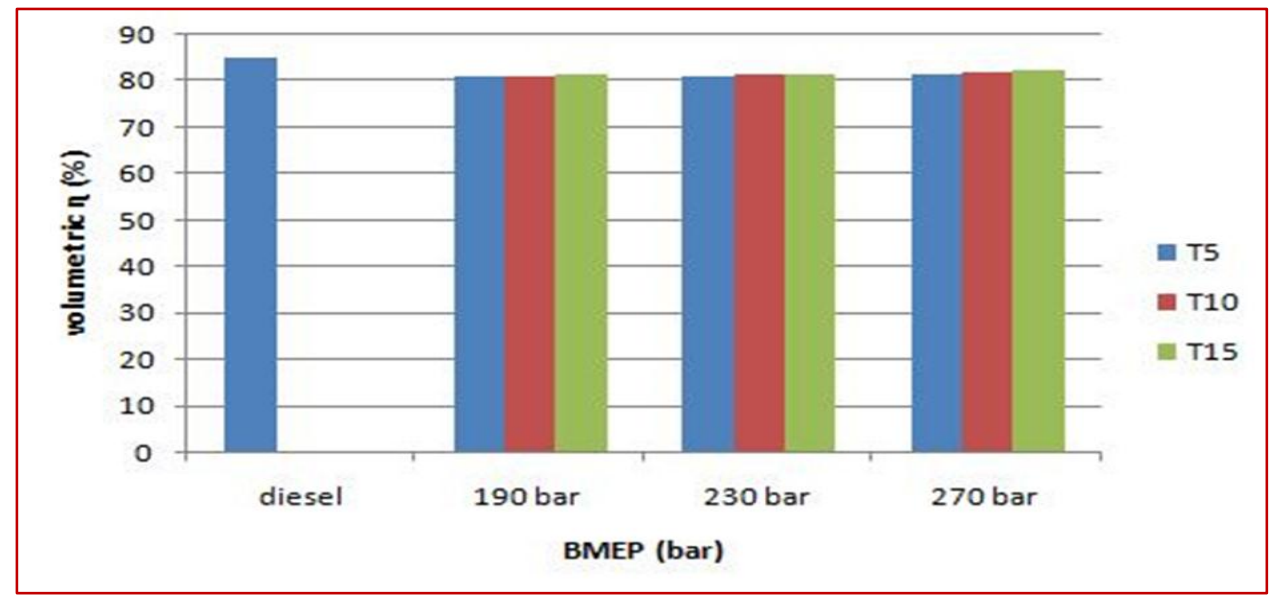

Figure 4 Volumetric efficiency versus percentage of blends at different injection pressures

Figure 5 manifests that exhaust gas temperature (EGT) is higher with pure diesel and decreases with blend. It is also observed that EGT decreases insignificantly with increasing injection pressures.

Figure 6 tells that smoke density is drastically higher with pure diesel and has decreased significantly after blending. It is also found that smoke density is decreasing with injection pressure. From Figure 7, it is clear that NOx percentage has increased after blending and also with injection pressure. The increase of NOx formation may be attributed to higher oxygen molecules of Tamarind Biodiesel.

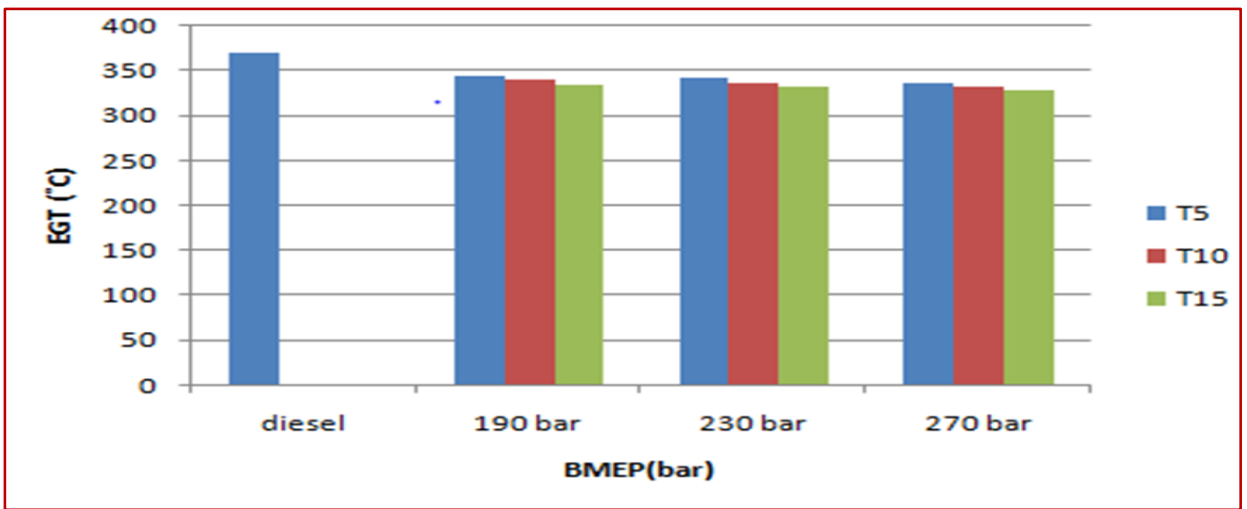

Figure 5 EGT versus percentage of blend at different injection pressures

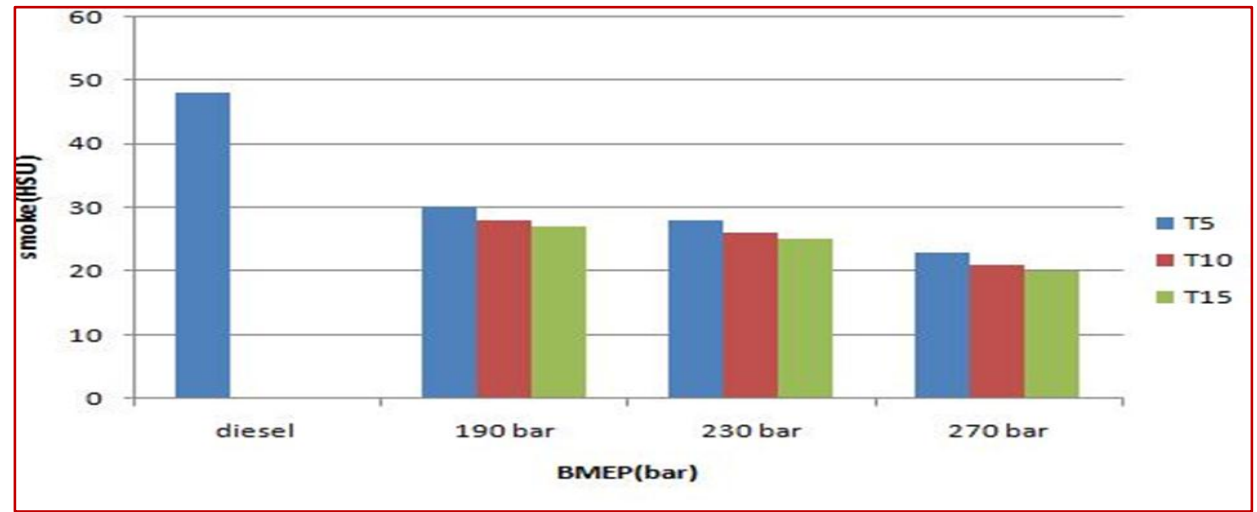

Figure 6 Smoke density versus percentage of blends at different injection pressures 
Bahar et al.

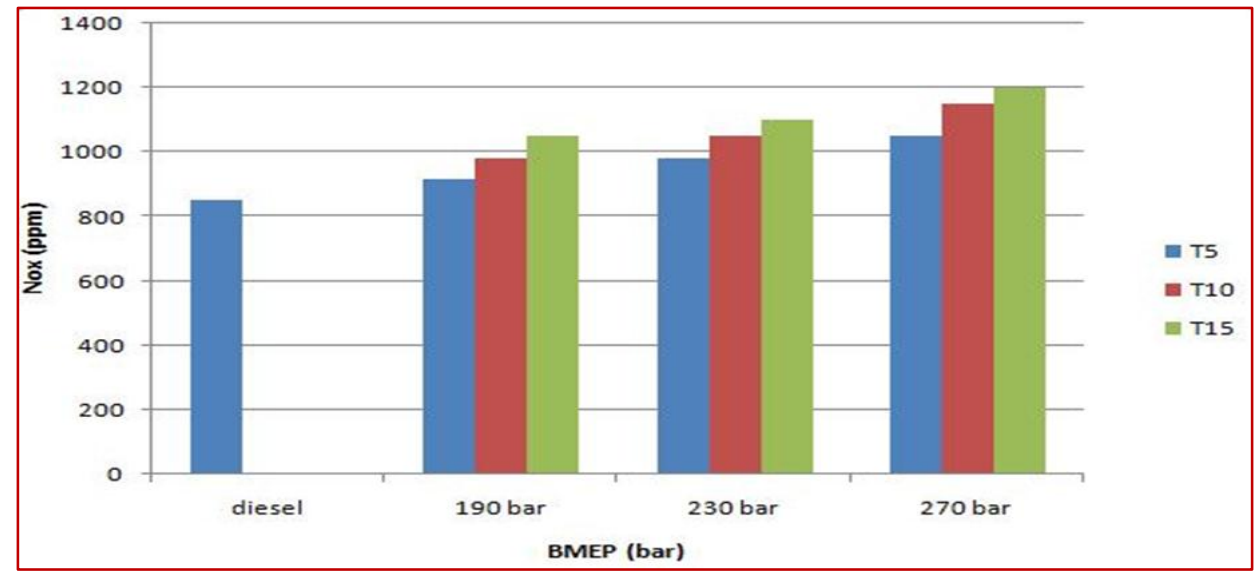

Figure 7 NOx percentage versus percentage of blends at different injection pressures

The cooling of exhaust gases before mixing with fresh air introduced to the engine does not affect its volumetric efficiency but it absorbs the heat of combustion. This leads to the increase in Nox emissions and improve in thermal efficiency.

\section{Conclusion and future work}

This study concludes that most of the performance parameters: BTE, volumetric efficiency, EGT, smoke density are in favor of Tamarind blend except oxides of nitrogen. The results shown that the Suitability of the liquid product obtained from tamarind seed can be chosen as an alternative fuel. In future, percentage of tamarind blend can be increased further with certain modifications in the engine to study the implications on engine performance and environmental pollution. Also this study can be extended to find out the economic viability of this project.

\section{Acknowledgment}

None.

\section{Conflicts of interest}

The authors have no conflicts of interest to declare.

\section{References}

[1] Dhana Raju V, Kishore PS. Effect of exhaust gas recirculation on performance and emission characteristics of a diesel engine fuelled with tamarind biodiesel. International Journal of Ambient Energy. 2018:1-10.

[2] Dhana Raju V, Kishore PS, Yamini K. Experimental studies on four stroke diesel engine fuelled with tamarind seed oil as potential alternate fuel for sustainable green environment. European Journal of Sustainable Development Research. 2018; 2(1):1-11.

[3] Patangi P, Shriprasadpatangi D, Malik A, Kumar. N S, Bhukya N. Performance characteristics of single cylinder C.I engine by using tamarind oil biodiesel. International Journal of Recent Trends in Engineering and Technology.2018; 4(1):255-63.

[4] Pohit G, Misra D. Optimization of performance and emission characteristics of diesel engine with biodiesel using grey-taguchi method. Journal of Engineering. 2013:1-8.

[5] Nigade SS. Performance and emission characteristics of CI engine operated on Madhuca Indica biodiesel using multi-objective optimization by applying Taguchi grey relational analysis. SAE International Journal of Fuels and Lubricants. 2016; 9(2):392-9.

[6] Rao KP, Rao BA. Parametric optimization for performance and emissions of an IDI engine with Mahua biodiesel. Egyptian Journal of Petroleum. 2017; 26(3):733-43.

[7] Natarajan S, Pitchandi K, Mahalakshmi NV. Optimization of performance and emission characteristics of PPCCI engine fuelled with ethanol and diesel blends using grey-Taguchi method. Journal of Thermal Science. 2018; 27(1):89-94.

[8] Avinash, Anwar KB, Gowreesh. Optimization of diesel engine parameters with blend of Pongamia biodiesel and diesel using Taguchi method. International Journal of Applied Engineering Research and Development. 2015; 5 (1):13-20.

[9] Venkatanarayana B, Ratnam CH. Application of Taguchi approach to optimize performance and emission parameters of single cylinder direct injection diesel engine using Karanja methyl ester. International Journal of Chemical Sciences. 2017; 15(4).

[10] Aydin H, Bayindir H. Performance and emission analysis of cottonseed oil methyl ester in a diesel engine. Renewable Energy. 2010; 35(3):588-92.

[11] Gopinath S, Nadanakumar V, Kannan M. Experimental investigation on injection parameters using Taguchi. IOSR Journal of Mechanical Engineering. 2014; 23-6.

[12] Kumar S, Navaneethakrishnan P, Kumar TS, Kumaragurubaran B. Performance optimization of diesel engine with watermelon seed oil blend using 
Taguchi-grey relational analysis. International Journal of Engineering Science. 2016; 6(5):5231-4.

[13] Kandasamy MM, Thangavelu M, Ganesan R. Investigation on the performance of diesel engine using various bio fuels and the effect of temperature variation. Journal of Sustainable Development. 2009; 2(3):176-82.

[14] Jawre SS, Lawankar SM. Performance analysis of kusum methyl ester as alternative bio-fuel in diesel engine with diethyl ether as additive. International Journal of Innovative Research and Development. 2014; 3(5):139-44.

[15] Vasukumar N, Subramanyam D, Tammineni L. Performance investigation of diesel engine using waste plastic pyrolysis oil and diesel blends. International Journal of Engineering Science. 2017; 7(11):15645-50.

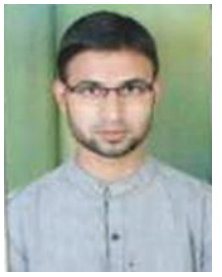

Mr. DilBahar received his B.Tech degree (with hons) in mechanical engineering from $\mathrm{F} / \mathrm{O}$ Engineering and Technology, JamiaMilliaIslamia (central university) New Delhi in 2010 and his M.Tech degree (First division) in Industrial engineering (Department of mechanical engineering) from Indian Institute of Technology Delhi in 2012. He has about 6 years of teaching experience in Rajiv Gandhi university of knowledge Technologies (RGUKT) Basar and National Institute of Technology (NIT) Jalandhar. Presently he is working as Assistant Professor in the Department of Mechanical engineering, RGUKT Basar, Nirmal District504107 (TS).

Email:dilbahar_me_iitd@rgukt.ac.in 